\title{
Consequences of lysine auxotrophy for Candida albicans adherence and biofilm formation
}

\author{
Iwona Gabriel ${ }^{\boxplus}$ and Michał Rychłowski² \\ 1Department of Pharmaceutical Technology and Biochemistry, Gdansk University of Technology, Gdańsk, Poland; ${ }^{2}$ Laboratory of Virus Molecular \\ Biology, Intercollegiate Faculty of Biotechnology University of Gdańsk - Medical University of Gdańsk, Gdańsk, Poland
}

\begin{abstract}
A number of factors are known to be involved in Candida albicans virulence, although biofilm development on the surfaces of indwelling medical devices is considered to promote superficial or systemic disease. Based on previously reported up-regulation of saccharopine and acetyllysine in biofilm cells and activation of the lysine biosynthesis/degradation pathway, we investigated the consequences of Candida albicans lysine auxotrophy on adhesion to host tissues and biofilm formation. Our data indicate that mutant strains lys $\Delta 21 / l y s \Delta 22$, defective in homocitrate synthase, and lys $\Delta 4$, defective in homoaconitase activity (the first two a-aminoadipate pathway enzymes), are able to adhere to mouse embryonic fibroblast cells (cell line NIH/3T3) to the same extent as a control strain SC5314. On the other hand, the auxotrophic mutant strains' development on mouse fibroblast monolayers was significantly reduced up to $5 \mathrm{~h}$ post infection. Although invasion into human-derived oral epithelial cells was unaltered, both mutant strains formed a significantly different biofilm architecture and demonstrated diminished viability during long term biofilm propagation.
\end{abstract}

Key words: Candida albicans, biofilms, adhesion, fungi, infection

Received: 14 September, 2016; revised: 13 December, 2016; accepted: 04 Jnauary, 2017; available on-line: 03 April, 2017

$\triangle$ e-mail: iwogabri@pg.gda.pl

Abbreviations: AAP a-aminoadipate pathway; CFU, colony forming unit; CFW, calcofluor white M2R; CSLM, confocal scanning laser microscopy; DMEM, Dulbecco modified Eagle medium; FBS, fetal bovine serum; LDH, lactate dehydrogenase; PBS, phosphate buffered saline; $\mathrm{PI}$, propidium lodide; $\mathrm{RHOE}$, reconstituted human oral epithelium; SMM, SkinEthic maintenance medium; XTT, sodium $3^{\prime}$-[1-[(phenylamino)-carbony]-3,4-tetrazolium]-bis(4-methoxy-6-nitro)benzene-sulfonic acid hydrate

\section{INTRODUCTION}

High death rates of people infected with HIV and those suffering from cancers are, inter alia, related to opportunistic infections including fungal infections (Miceli et al., 2011). Infections of mammalian tissues by pathogenic yeasts of the Candida spp. primarily begin with adherence and colonization of an artificial or a biotic host surface, leading to the formation of surface-attached communities known as biofilms. Formation of Candida biofilm is a complex process requiring coordination of various signaling pathways. The ability to form heterogeneous biofilm structure is associated with the ability to cause infection, particularly on artificial medical devices and in patients with impaired immune response (Kojic \& Darouiche, 2004). The following key processes involved in Candida biofilm development are crucial: adhesion, fil- amentation and communication between cells (Wächtler et al., 2011). In context of antifungal therapy, biofilms are defined as highly structured communities of microorganisms that are either surface associated or attached to one another and are enclosed within a self-produced protective extracellular matrix. The advantages to an organism of forming a biofilm include protection from the environment, resistance of physical and chemical stress, metabolic cooperation, and a community-based regulation of gene expression. In recent years, there has been an increased appreciation of the role that fungal biofilms play in human diseases, as microbes growing within biofilms exhibit unique phenotypic characteristics in comparison to their planktonic counterpart cells, particularly an increased resistance to antimicrobial agents (Seneviratne et al., 2008; Ramage et al., 2012).

Key processes during infection, such as adhesion, yeast to mycelium transformation, penetration and destruction of the host cells, are associated with the expression of many proteins. Targeted and untargeted profiling of metabolites involved in biofilm and planktonic growth of $C$. albicans indicates a striking difference in the metabolite profiles, ranging from energy metabolism to amino acid biosynthesis (Zhu et al., 2013; Chen et al., 2014). Several amino acids, including alanine, aspartate, asparagine, threonine, valine and glycine, are upregulated almost during the whole process of biofilm development when compared to the planktonic cells, indicating that amino acid metabolism plays a critical role in C. albicans biofilm formation. The amino acid-related metabolites, including betaine, putrescine, $N$-acetylputrescine, acetyllysine and saccharopine were also identified as up-regulated. Saccharopine and acetyllysine are both lysine-related metabolites. Saccharopine is an intermediate of $\alpha$-aminoadipate pathway of lysine biosynthesis, and acetyllysine is a degradation product of lysine. Quantitative analysis had shown that the lysine content increased by 2.11 fold in the biofilm cells in comparison to the planktonic ones. Along with up-regulation of saccharopine and acetyllysine in the biofilm cells, activation of the lysine biosynthesis/degradation pathway was observed (Chen et al., 2014). Previous research indicated that Gcn4p, a general regulator of amino acid biosynthesis, was required for normal biofilm formation (Yeater et al., 2007), and lysine biosynthesis was highly regulated by Gcn4p in yeast (Busch et al., 2002). On the other hand, selective inhibitors of enzymes present in the biosynthetic routes leading to biosynthesis of human essential amino acids may become useful antimicrobials, including antifungal agents (Jastrzębowska \& Gabriel, 2015). Azoxybacilin, an aliphatic amino acid with an azoxy sidechain, isolated from B. cereus, inhibits expression of the 
gene encoding an enzyme involved in the biosynthesis of L-methionine and has a broad spectrum of antifungal activity (Aoki, 1996). Another compound from this group is 5-hydroxy-4-oxo-L-norvaline, known as RI-331. This is an effective inhibitor of homoserine dehydrogenase involved in biosynthesis of amino acids belonging to the aspartate family (Yamaki et al., 1990). Both compounds display a high antifungal in vitro and in vivo activity and low toxicity.

In Candida albicans, as in other higher fungi, de novo Llysine biosynthesis proceeds through the $\alpha$-aminoadipate pathway (AAP) in a series of transformations consisting of eight stages catalyzed by seven enzymes (Fig. 1). Despite some analogies to the reactions of the Krebs cycle, the first three reactions are unique for the $\alpha$-aminoadipate pathway and are very specific for higher fungi. Homocitrate synthase catalyzes condensation of $\alpha$-ketoglutarate with AcCoA, the first and committed step in the pathway; it is highly regulated to economize the use of resources, and the reaction it catalyzes is thought to be the rate-limiting step in the pathway (A). Homocitrate is isomerized to homoisocitrate upon the action of homoaconitase (B) and then homoisocitrate dehydrogenase carries out oxidation of homoisocitrate to $\alpha$-ketoadipate (C). The second phase starts from the transamination leading to the creation of $\mathrm{L}-\alpha$-aminoadipate (D), followed by reduction of the $\delta$-carboxyl function affording $\mathrm{L}-\alpha$-aminoadipic- $\delta$-aldehyde (E) which is subsequently

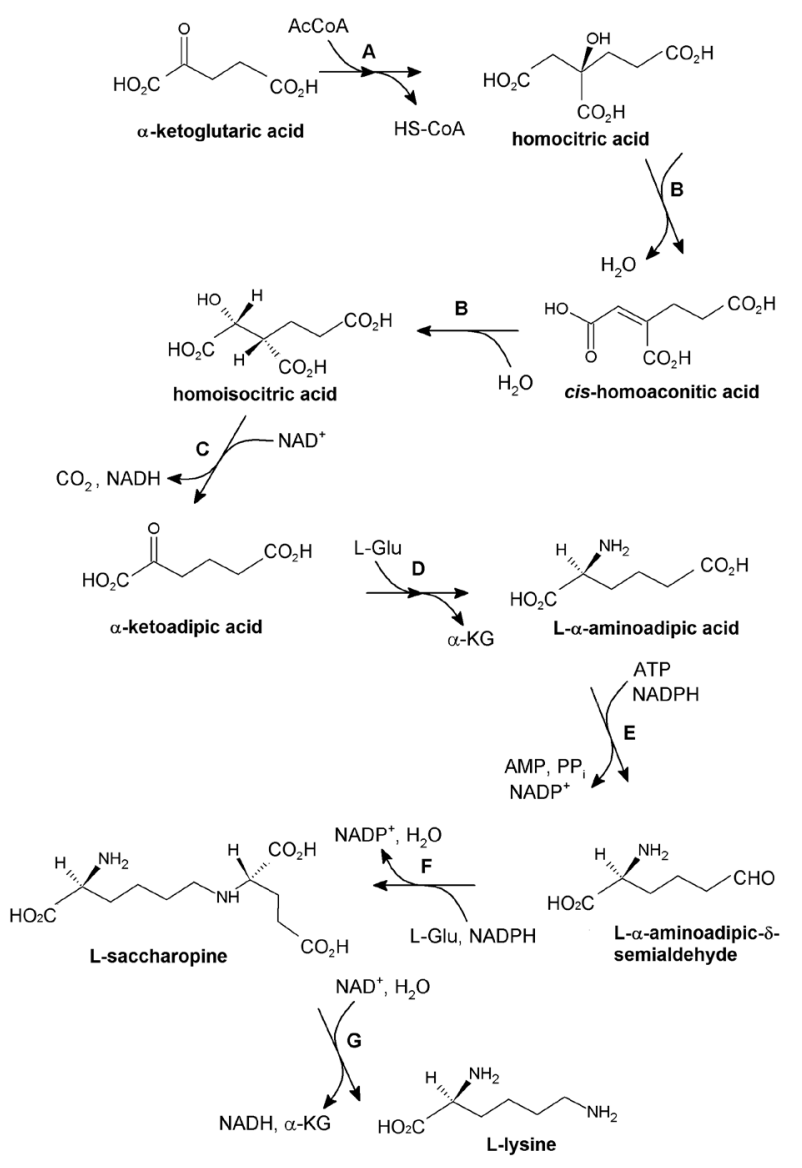

Figure 1. Enzymes of the fungal a-aminoadipate pathway to lysine:

(A) homocitrate synthase; (B) homoaconitase; (C) homoisocitrate dehydrogenase; (D) aminoadipate aminotransferase; (E) aminoadipate reductase; (F) saccharopine reductase; (G) saccharopine dehydrogenase. condensed with L-Glu to form saccharopine (F), which is finally split into L-Lys and $\alpha$-ketoglutarate $(G)$.

The pathogenic properties of fungi carrying mutations resulting in lysine auxotrophy have been evaluated previously, but the results obtained so far are equivocal. Some reports demonstrated avirulence or attenuated virulence of lysine auxotrophs (Tang et al., 1994; Liebmann et al., 2004; Schöbel et al., 2010) but others showed indicated equivalent virulence (Kingsbury et al., 2006; Kur et al., 2010).

The potential of AAP enzymes as targets for antifungal chemotherapy has inspired the design and synthesis of structural analogs of AAP intermediates, which have been tested for antifungal activity and/or inhibition of the AAP enzymes. Some of these compounds had showed moderate inhibition of fungal growth that could be partially restored by the presence of L-lysine in the growth medium (Palmer et al., 2004; Gabriel et al., 2013).

In our previous works we have described some phenotypic consequences of C. albicans LYS21 and LYS22 (encoding two isoforms of homocitrate synthase) or LYS4 (encoding homoaconitase) genes disruption (Kur et al., 2010; Gabriel et al., 2014). In this study we report what are the consequences of Candida albicans lysine auxotrophy for adhesion to host tissues and plastic surfaces and for the fungi biofilm-forming ability.

\section{MATERIALS AND METHODS}

Strains and growth conditions. The wild type SC5314 cells (Gillum et al., 1984) were maintained on minimal agar plates containing $6.7 \mathrm{~g}$ of Yeast Nitrogen Base w/o amino acids, $2 \mathrm{~g}$ of glucose, and $1.5 \%$ of agar (YNB). C. albicans lysine auxotrophic strains lys $\Delta 21 /$ lys $\Delta 22$ (Kur et al., 2010) and lys $\Delta 4$ (Gabriel et al., 2014) were maintained on YNB supplemented with L-Lys $\left(60 \mu \mathrm{g} \mathrm{ml} \mathrm{m}^{-1}\right)$. Candida strains used for RHOE infection were routinely grown in the YPD medium $(10 \mathrm{~g}$ of yeast extract, $20 \mathrm{~g}$ of peptone and $20 \mathrm{~g}$ glucose per liter) at $30^{\circ} \mathrm{C}$. For growth on solid media, $1.5 \%$ agar was added (YPD agar medium).

Biofilm development. Candida biofilms were developed with the use of a microtiter plate-based model, according to previously published protocols (Pierce et al., 2008; Uppuluri et al., 2009). Briefly, cells were grown in the YPD medium overnight at $30^{\circ} \mathrm{C}$, washed twice with sterile phosphate buffered saline (PBS) and re-suspended in RPMI1640, RPMI1640 supplemented with $5 \mathrm{mM} \mathrm{L-}$ Lys, DMEM or SMM (SkinEthic Maintenance Medium; SkinEthic Laboratories) at cell density of $10^{6}$ cells $\mathrm{ml}^{-1}$. This inoculum $(200 \mu \mathrm{l})$ was added to each well of a 96well flat-bottomed microplate (BD Non-Tissue Culture Treated Plate, 96-well). After a $24 \mathrm{~h}, 48 \mathrm{~h}$ or $72 \mathrm{~h}$ incubation at $37^{\circ} \mathrm{C}$ to allow biofilm formation, the wells were washed twice with PBS to remove any non-adherent cells, and the XTT reduction assay, performed as previously described (Ernst \& Rogers, 2005), was used to quantify viable cells constituting the biofilm layers in the wells.

Adhesion of Candida cells to the fibroblasts. The adhesion ability of $C$. albicans to mouse fibroblasts was assessed using a previously described method (Budzyńska et al., 2014). Fibroblast cells of the NIH/3T3 line (ATCC ${ }^{\circledR}$ CRL-1658 ${ }^{\mathrm{TM}}$ ) were cultured in DMEM with $4500 \mathrm{mg} \mathrm{l}^{-1}$ glucose, L-glutamine and $\mathrm{NaHCO}_{3}$ (Sigma), supplemented with $10 \%$ heat inactivated Fetal Bovine Serum (FBS) (Sigma), and 1\% penicillin/streptomycin (Cytogen), in 6-well tissue culture plates (BD). Cells were 
incubated at $37^{\circ} \mathrm{C}$ in a humidified atmosphere enriched with $5 \% \mathrm{CO}_{2}$. For infection, the semi-confluent monolayers were washed with PBS and $1.5 \times 10^{2}$ C. albicans cells were added to each well. After $45 \mathrm{~min}$ of incubation, monolayers were washed once with PBS to remove unbound yeasts, and overlayered with melted YPD agar medium. After $24 \mathrm{~h}$ incubation at $37^{\circ} \mathrm{C}$, Candida colonies were counted. The results are shown as a number of adherent yeast cells (CFU/well, colony forming units per well) \pm S.D.

Candida albicans infection of NIH/3T3 monolayer and cell staining. For each experiment, C. albicans cells were cultured in the YPD medium for $16 \mathrm{~h}$ at $30^{\circ} \mathrm{C}$. After incubation, cells were harvested by centrifugation and washed three times with PBS. The yeast cells were then counted and adjusted to a concentration of $2 \times 10^{6}$ cells $\mathrm{ml}^{-1}$ in DMEM. For infection, the semi-confluent monolayers of $\mathrm{NIH} / 3 \mathrm{~T} 3$ cells in 6-well plates (BD, Tissue Culture Plate) were washed with PBS and $2 \mathrm{ml}$ of standardized suspensions of $C$. albicans cells were added to each well. Control samples were treated with $2 \mathrm{ml}$ aliquots of DMEM. Infected monolayers were incubated for 2,5 and $9 \mathrm{~h}\left(37^{\circ} \mathrm{C}\right.$, humidified atmosphere, $5 \% \mathrm{CO}_{2}$ ). After incubation, the maintenance medium was removed, infected monolayers were fixed in a buffered neutral 10\% formalin solution for $10 \mathrm{~min}$ and Gram stained (Harrington et al., 2007) with fuchsine to counter-stain the fibroblast cells. Biofilm formation was monitored by bright-field light microscopy with an inverted system microscope (Zeiss Telaval 3). To analyze the fibroblast damage, the semi-confluent monolayers of NIH/3T3 cells in 24-well plates (BD, Tissue Culture Plate) were washed with PBS, and $1 \mathrm{ml}$ of $2 \times 10^{6}$ cells $\mathrm{ml}^{-1}$ suspensions of Candida cells in SMM medium were added to each well. Control samples were inoculated with $1 \mathrm{ml}$ of pure medium. Infected monolayers were incubated for $16 \mathrm{~h}\left(37^{\circ} \mathrm{C}\right.$, humidified atmosphere, $5 \%$ $\mathrm{CO}_{2}$ ). After incubation, the maintenance medium was removed to determine the release of lactate dehydrogenase (LDH).

Infection of RHOE. To investigate the in vitro infection of oral mucosa by Candida strains, a reconstituted human oral epithelium (RHOE) model (SkinEthic Laboratories) was used (Schaller et al., 2006). C. albicans cells were cultured in the YPD medium for $16 \mathrm{~h}$ at $30^{\circ} \mathrm{C}$. After incubation, cells were harvested by centrifugation, washed three times with PBS, suspended in SMM and adjusted to cell density of $2 \times 10^{6}$ cells $\mathrm{ml}^{-1}$. RHOE tissue inserts $\left(0.5 \mathrm{~cm}^{2}\right)$ were placed in 24-well tissue culture plates (BD) with SMM according to the manufacturer's instructions. For infection, $1 \mathrm{ml}$ of standardized C. albicans suspensions were placed directly onto the RHOE tissue inserts. Control samples were inoculated with $1 \mathrm{ml}$ of SMM. Infected tissues were incubated at $37^{\circ} \mathrm{C}$ in a humidified atmosphere enriched with $5 \% \mathrm{CO}_{2}$ for $16 \mathrm{~h}$. After incubation, the maintenance medium was removed to determine the release of lactate dehydrogenase ( $\mathrm{LDH}$ ) and the RHOE tissues were rinsed twice with PBS to remove non-adherent Candida cells. Tissue sections were cut and placed onto microscope slides for alive staining.

Damage assay. The release of $\mathrm{LDH}$ from RHOE or NIH/3T3 monolayers into the culture medium was used as a measure of epithelial cell damage. The LDH concentration was determined after $16 \mathrm{~h}$ using the CytoTox-ONE kit (Promega) according to the manufacturer's instructions. Relative tissue damage was calculated as the percentage of $\mathrm{LDH}$ release compared with $\mathrm{RHOE}$ or NIH/3T3 infected by C. albicans SC5314 control strain (estimated as $100 \%$ tissue damage level).
Confocal Scanning Laser Microscopy (CSLM). The degree of colonization and the morphology characterization of $C$. albicans cells grown on the surface of alive tissues were assessed by CSLM following direct staining with Calcofluor White M2R (CFW), $10 \mu \mathrm{g} \mathrm{ml} \mathrm{m}^{-1}$ and Propidium Iodide (PI), $10 \mu \mathrm{g} \mathrm{ml} \mathrm{m}^{-1}$. Stained sections were washed, mounted with $0.2 \mathrm{~mol} \mathrm{l}^{-1}$ Tris- $\mathrm{HCl} \mathrm{pH} 8.0$ in $90 \%$ glycerol, viewed and analyzed by CSLM using a Leica TCS SP8-X White Light Laser Confocal Microscope (Leica, Wetzlar, Germany). Sections were scanned sequentially through their depth using settings for fluorescence of CFW (ex/em max: 365-395/420 nm), PI (ex/em max: 536/617 nm) and with a $\times 63$ oil objective lens.

Statistical analysis. Data were presented as an arithmetic mean \pm S.D. The results of Candida biofilm viability were compared using a one-way analysis of variance (ANOVA) by applying a Tukey multiple comparisons test. Statistically significant differences were set at $P<0.05$.

\section{RESULTS AND DISCUSSION}

\section{Adhesion of $C$. albicans cells to mouse fibroblasts and infection development}

Adhesion of C. albicans to various epithelia is necessary for it to occupy the different niches of the human body and to penetrate tissues in order for infection development. To study the early events during this close host-pathogen interaction we established an in vitro adhesion assay. By using such an assay, we first wished to analyze whether wild-type and mutant strains of $C$. albicans adhere to fibroblast monolayer to variable extents. In this context, the adhesion ability of C. albicans SC5314 and C. albicans lys $\triangle 21 /$ lys $\triangle 22$, lys $\triangle 4$ mutant strains to NIH/3T3 cell line was assessed using the methodology of Budzyńska et al. (2014). Results of this experiment, presented in Fig. 2, indicate that there was no statistically significant difference in the number of viable SC5314, lys $\Delta 21 /$ lys $\triangle 22$ and lys $\Delta 4$ cells that adhered to mouse fibroblasts. One may thus conclude that that lysine auxotrophy resulting from deletion of the genes encoding enzymes catalyzing the first two reactions of the AAP pathway has no effect on primary adhesion of yeast cells to fibroblasts. On the other hand, a microscopic inspection of the infection development by $C$. albicans cells on NIH/3T3 monolayer revealed a significant difference between the mutant and control cells. A significant reduction of growth and the degree of morphological changes of the first one was

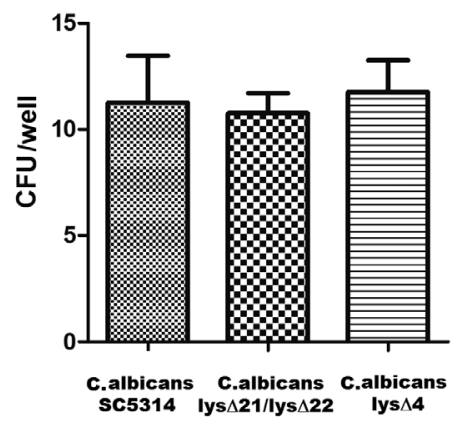

Figure 2. Adherence of $C$. albicans strains to NIH/3T3 fibroblast monolayer.

The experiments were performed in triplicate and the results are shown as CFU number of yeast cells per well \pm S.D. 
C. albicans SC5314
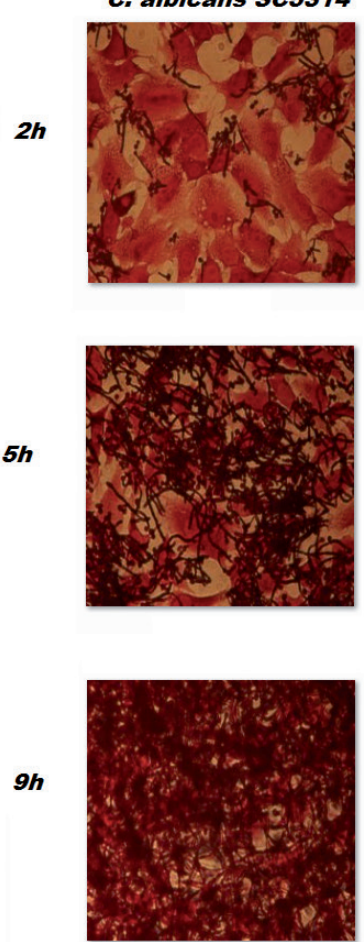

lys $421 / / y s \Delta 22$
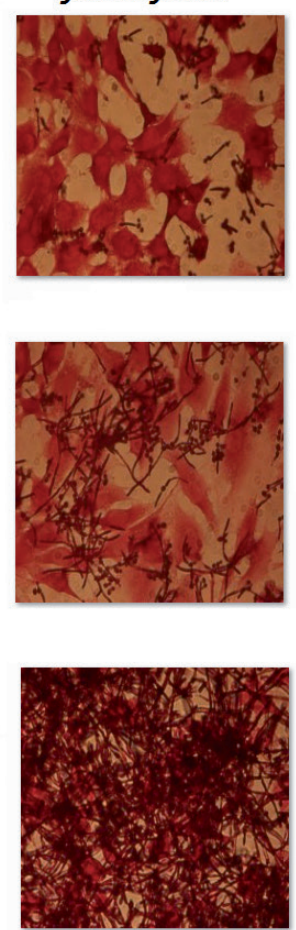

lys $\Delta 4$
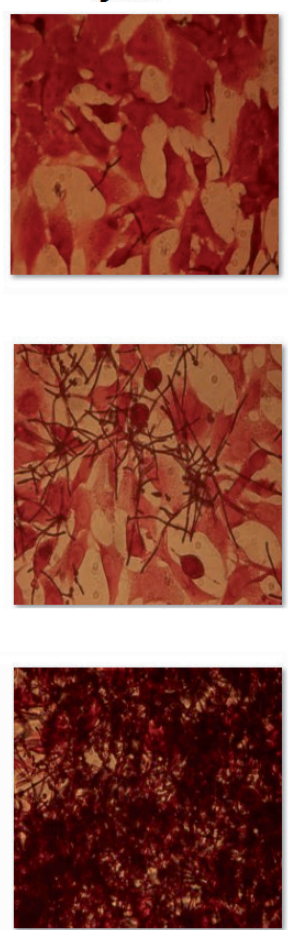

Control
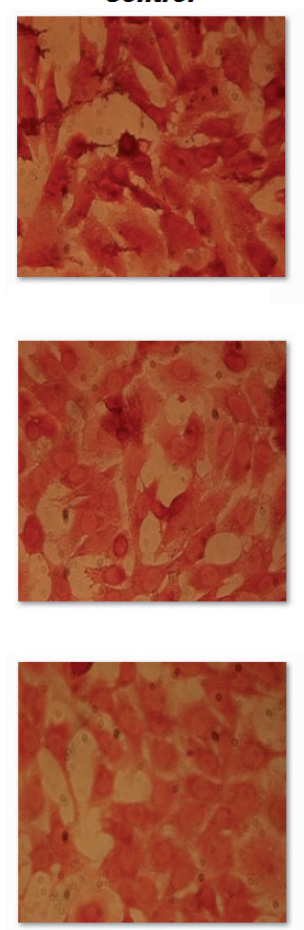

Figure 3. Light microscopy images of C. albicans SC5314 and lysine auxotrophic mutant strains' development on NIH/3T3 cell line monolayer in DMEM.

The control contained pure medium. The different panels show photomicrographs taken at various time points during biofilm development, as indicated (magnification $\times 40$ ). C. albicans and murine cells were Gram stained and counterstained with fuchsine, respectively. The experiments were performed in triplicate.

observed after $2 \mathrm{~h}$ and $5 \mathrm{~h}$ of incubation (Fig. 3). This difference was especially notable after $5 \mathrm{~h}$, when the growth of SC5314 cells was very extensive and hyphae from neighboring microcolonies merged into an intricate network of cells mostly composed of filamentous forms. In contrast, growth of the lys $\Delta 21 /$ lys $\triangle 22$ and lys $\triangle 4$ mutants was much less efficient. The difference between control and mutant cells disappeared after $9 \mathrm{~h}$ of incubation. Our results indicate that mutant cells are able to adhere to $\mathrm{NIH} / 3 \mathrm{~T} 3$ cells monolayer similarly to the wild type C. albicans SC5314. On the other hand, lysine auxotrophy results in retardation of growth and development of biofilm formation in the early stage of infection on mouse fibroblasts. It should be noted that L-Lys concentration in DMEM supplemented with $10 \%$ FBS (over $1 \mathrm{mM}$ ) is higher than the critical level estimated in previous studies (Kur et al., 2010; Gabriel et al., 2014), necessary for unaltered growth of C. albicans lys $\Delta 21 /$ lys $\triangle 22$ and lys $\Delta 4(\sim 0.12 \mathrm{mM})$. Therefore, it seems likely that the observed retardation of infection development is not a consequence of general growth impairment.

Majority of genes involved in protein synthesis are exclusively overexpressed during biofilm development (early and intermediate stage). One reason for this activation of the protein synthesis machinery could be that biofilms grow faster than planktonic populations. LYS21, LYS4 and LYS9 (encoding saccharopine dehydrogenase) genes involved in lysine biosynthesis were also reported to be overexpressed between different time points of biofilm development $(2.7,2.4$ and 2.5fold change between $6 \mathrm{~h}$ and $12 \mathrm{~h}$ on denture, respectively) (Yeater et al., 2007). It should be noted that the lysine auxotrophic cells growth and biofilm devel- opment retardation at the early stages of infection of mouse fibroblasts that we have observed might be due to the lack of homocitrate synthase (Lys21p, Lys22p) and homoaconitase (Lys4p) activity.

\section{C. albicans biofilm formation}

Biofilm formation is a highly complex phenomenon and its structure is highly dependent on the type of surface and the media (Chandra et al., 2001; Uppuluri et al., 2009). In this context, we were interested to determine whether in principle there is a difference between biofilm forming ability of mutant strains and wild-type SC5314 on abiotic surfaces. Second, we also wanted to analyze the biofilm maturation in the long term. For this purpose, formation of biofilms and viability of biofilmforming cells of $C$. albicans lysine auxotrophic mutants were tested in two media, RPMI1640, which is commonly used to form biofilms in vitro and SMM, to analyze whether $C$. albicans biofilms may develop under the conditions used for RHOE infection. C. albicans biofilms were developed for 24, 48 and $72 \mathrm{~h}$ in 96-well microtiter plates. Metabolic activity of the biofilm cells was measured by the XT'T assay.

Results of this experiment, shown in Fig. 4, reveal that $C$. albicans cells grown in a biofilm layer in SMM appeared to be at least threefold less metabolically active than the biofilm cells in the RPMI1640 medium. No statistically significant difference in metabolic activity between mutant cells auxotrophic for lysine (lys $\Delta 21$ ) lys $\triangle 22$ and lys $\triangle 4$ ) and wild-type SC5314 in SMM was noted. On the other hand, in RPMI1640, decrease of metabolic activity of lys $\Delta 21 /$ lys $\Delta 22$ was observed after $24 \mathrm{~h}$. As further biofilm maturation occurred over $24 \mathrm{~h}$, 

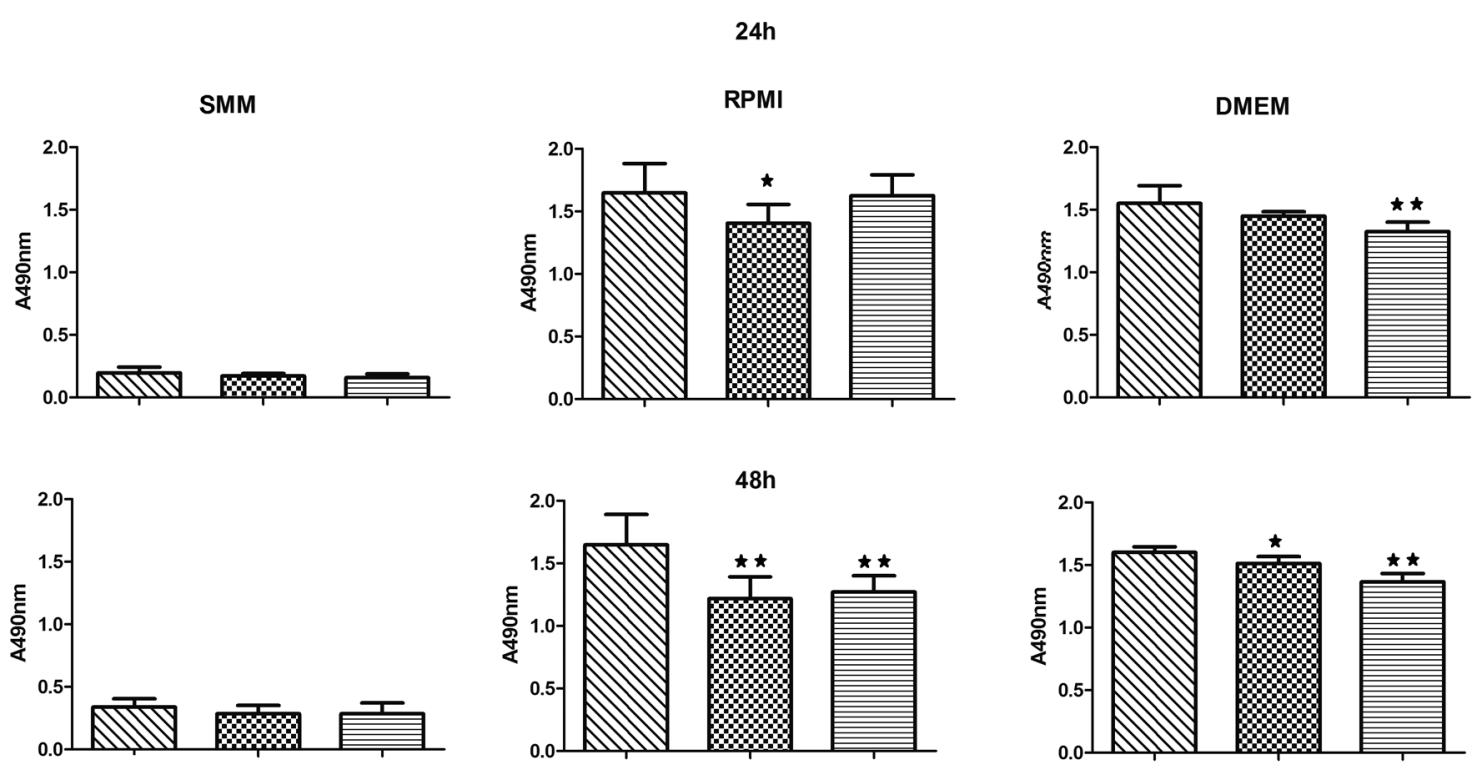

$72 \mathrm{~h}$
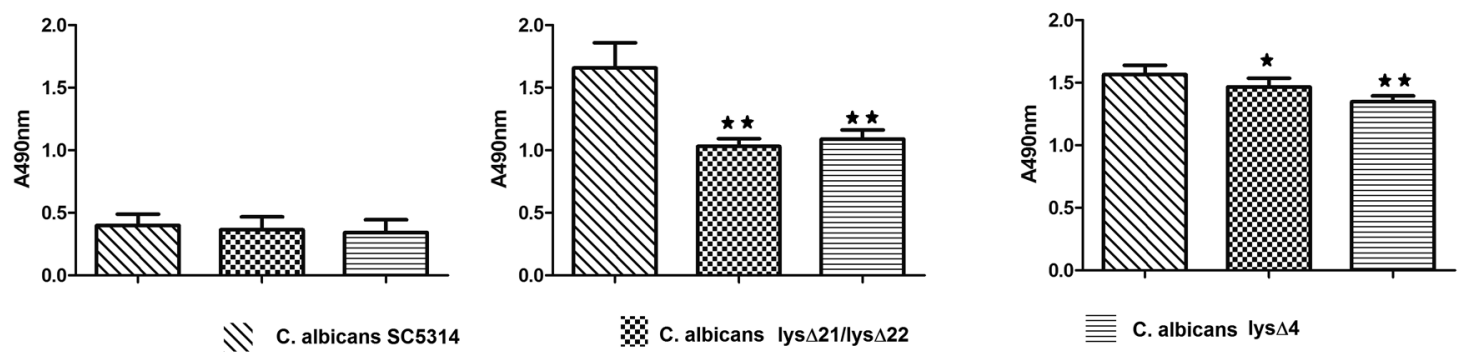

Figure 4. Metabolic activity of C. albicans biofilms in SMM, DMEM and RPMI1640 as determined by XTT colorimetric method. ${ }^{*}$ Result statistically significant at the significance level $p<0.05 ;{ }^{* *} p<0.01$. The experiments were performed in five replicates.

significant differences were observed. Cells present in mature (i.e., 48 -h; $72 \mathrm{~h}$ old) C. albicans hys $\Delta 21 /$ hys $\Delta 22$ and hys $\triangle 4$ biofilms demonstrated a strongly diminished viability. The same differences in metabolic activity between mutant cells auxotrophic for lysine (bys $\Delta 21$ / ys $\Delta 22$ and ys $\triangle 4$ ) and wild-type SC5314 were noted after $48 \mathrm{~h}$ and $72 \mathrm{~h}$ in RPMI1640 supplemented with additional Llysine (5 mM) (data not shown). We found that the lysine auxotrophic mutant cells are able to form biofilms but their viability during long term propagation in a medium routinely used to study biofilms is altered. Due to the increased lysine content in the biofilm cells when compared to the planktonic ones (Chen et al., 2014), one may thus anticipate that C. albicans lysine auxotrophs' biofilm forming ability is reduced by inadequate levels of this amino acid. Results of the experiment performed in RPMI1640 medium with additional $5 \mathrm{mM}$ L-Lys indicate that diminished viability of $C$. albicans bys $\Delta 21 /$ lys $\triangle 22$ and lys $\triangle 4$ mature biofilms does not depend on that amino acid concentration. On the other hand, large biomass increase that begins around $12 \mathrm{~h}$ of biofilm development, demands energy and utilizes specific transporters for amino acids, sugars, ions, oligopeptides and lactate/ pyruvate. GAP4 (general amino acid permease) gene expression was reported to be up-regulated in the biofilm at that stage of development (2.3-fold change at $12 \mathrm{~h}$ versus $6 \mathrm{~h}$, and 3.7-fold change at $12 \mathrm{~h}$ versus $48 \mathrm{~h}$ ) (Yeater et al., 2007). Amino acid transporters' activity might enable lysine auxotrophic cells to form biofilm but its progres- sion to maturity stage $(48 \mathrm{~h})$ is altered. Moreover, positively charged molecules, such as lysine, may not be able to freely diffuse through the polysaccharide extracellular material present in a mature biofilm to fulfill the auxotrophy. It is known, for example, that fluoroquinolones penetrate $P$. aeruginosa biofilms readily, whereas penetration by positively charged aminoglycosides is retarded (Drenkard, 2003). Similarly, fluconazole permeates single-species Candida biofilms more rapidly than flucytosine (Al-Fattani \& Douglas, 2004).

\section{Infection of reconstituted human oral epithelium (RHOE)}

In vitro tissue model of oral candidosis was chosen because of the fact that this three-dimensional infection model is well described in the literature and enabled us to simultaneously analyze biofilm structure, penetration and destruction of the host cells. The CSLM visualization of fungal biofilms grown on model tissues reveals that both, the mutant (bys $\Delta 21 /$ ys $\Delta 22$ and hys $\Delta 4$ strains) and the wild type C. albicans SC5314 cells, formed a biofilm-like structure, where most of the fungal cells were present as hyphae, although the tissue penetration patterns seems to be different (Fig. 5). Some differences in biofilm structure and density between mutants and SC5314 cells were observed. Biofilms formed by lysine auxotrophic mutants on the RHOE surface appeared to be thicker $(\sim 60 \mu \mathrm{m})$, though less dense than those produced by the wild-type strain $(\sim 30 \mu \mathrm{m})$. Moreover, ap- 

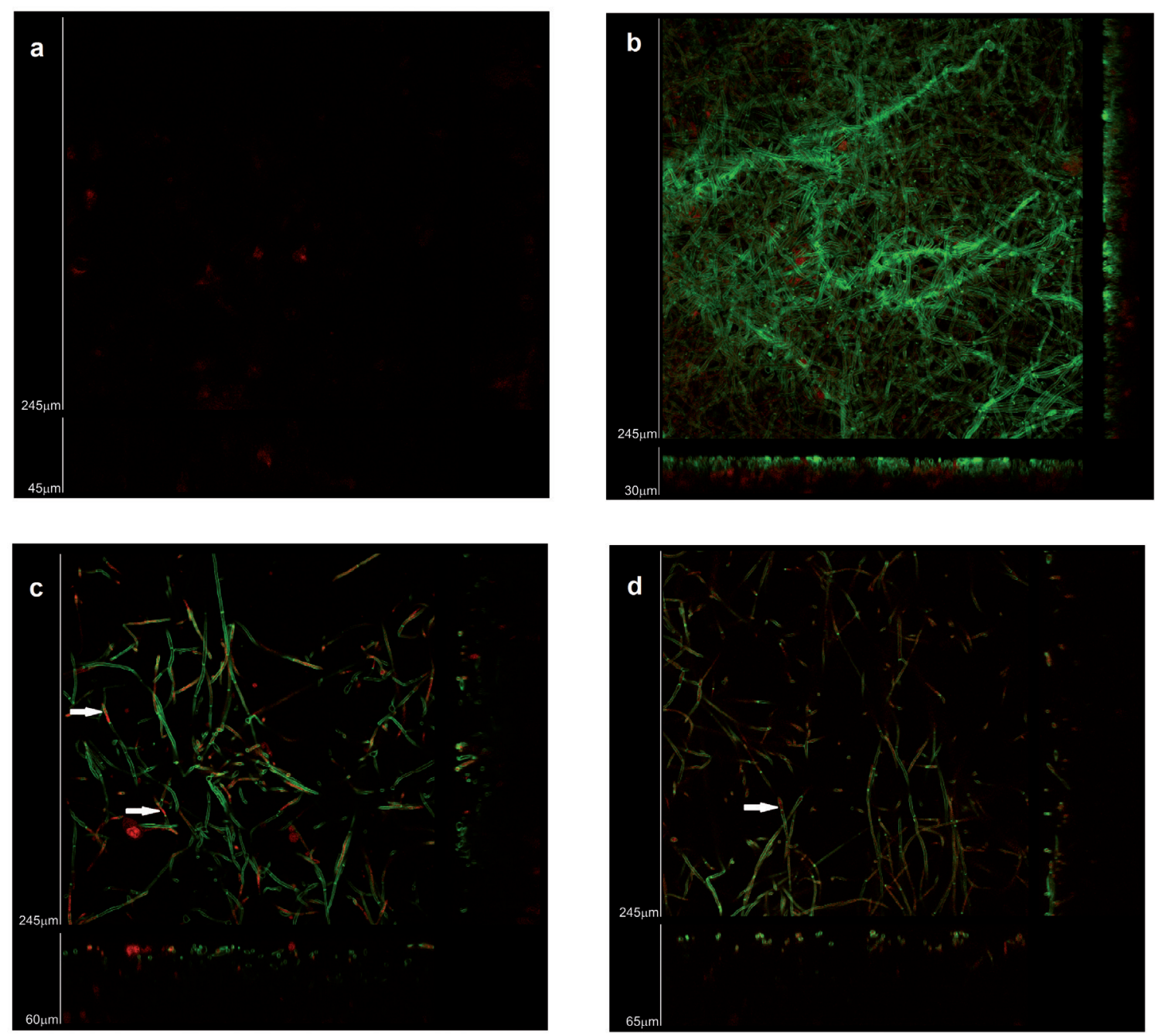

Figure 5. The viability of $C$. albicans cells and structural framework of biofilms as detected by CSLM.

Tissue devoid of fungal cells (a) and after the infection by SC5314 (b), lys $\Delta 21 / l y s \Delta 22$ (c) and lys $\Delta 4$ (d) strains were stained with CFW and PI. Dead C. albicans cells are indicated with white arrows.

parent gaps among mutant cell clusters and deeper tissue penetration were observed. C. albicans cell viability was also analyzed by propidium iodide staining. Our results indicate that both, the wild type and mutant cell infection causes fibroblast cells death (data not shown). Moreover, in biofilms formed by lysine auxotrophic lys $\Delta 21 /$ lys $\Delta 22$ and lys $\triangle 4$ cells, there were more non viable fungal cells than in those constituted by SC5314 (Fig. 5).

\section{In vitro tissue damage by lysine auxotrophic mutants}

The extent of RHOE and NIH/3T3 tissue damage by fungal biofilms was quantified by determination of the LDH activity. Both models differ inter alia in structure of the infected surface. The NIH/3T3 cell line is one of the most commonly used fibroblast cell lines and grows as monolaver, while the three-dimensional infection model (RHOE) enabled us to analyze penetration and destruction of the host cells. In this assay, the C. glabrata DSM11226 cells were used as a negative control, since this pathogenic yeast is known to be unable to form hyphae and is RHOE non-invasive (Schaller et al., 2002; Jayatilake et al., 2006). Results shown in Fig. 6 indicate that the tissue damage due the $C$. albicans biofilms was indeed more profound than that caused by the $C$. glabrata strain, thus confirming the previous observation of
Silva et al. (2011). No statistical differences were observed with respect to the wild type strain for $C$. albicans lys $\Delta 21 /$ lys $\triangle 22$ and lysD4 RHOE infection, despite more extensive tissue penetration, as indicated by the CSLM microscopy images (Fig. 5). The same results concerning the LDH activity were obtained for the NIH/3T3 monolayer infection model. Our experiments revealed

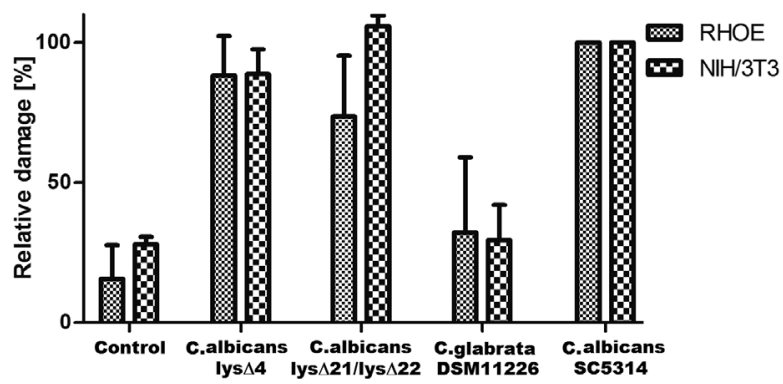

Figure 6. Relative tissue damage by C. albicans lys $\Delta 21 / l y s \Delta 22$, lys $\Delta 4$ and $C$. glabrata DSM11226 calculated as the percentage of $\mathrm{LDH}$ release compared with $\mathrm{RHOE}$ infected by $C$. albicans SC5314 control strain (estimated as $100 \%$ tissue damage level) \pm S.D.

All experiments were performed in duplicate and on two separate occasions. 
that although lysine auxotrophic mutant biofilm structure was observed to have less filamentation and have gaps between cell clusters, while SC5314 produced biofilms with a thick and dense structure of hyphae, the ability to destroy the reconstituted human oral epithelium seemed to be comparable.

In conclusion, for the first time, here we have systematically characterized the structure and composition of biofilms of C. albicans lysine auxotrophic mutants. We observed that C. albicans lys $\Delta 21 /$ lys $\triangle 22$ and lys $\Delta 4$ mutant strains exhibited a significant delay of growth in the early stages of biofilm development on the mouse fibroblast monolayers. This effect might be related to the previously reported up-regulation of LYS21 and LYS4 genes. Moreover, both mutant strains demonstrated a diminished viability during long term biofilm propagation. Although the morphological and architectural characteristics of the resulting biofilms are different from those formed by the wild type $C$. albicans, invasion of the human-derived oral epithelial cells seemed to be unaltered.

\section{Conflict of interest}

Authors declare no conflict of interest.

\section{Acknowledgements}

Financial support of these studies by the National Science Centre, Poland (grant No. 2015/17/B/NZ6/04248 awarded to IG ) is gratefully acknowledged.

\section{REFERENCES}

Aoki T (1996) Antifungal azoxybacillin exhibits activity by inhibiting gene expression of sulfite reductase. Antimicrob Agents Chemother 40: 127-132.

Al-Fattani MA, Douglas LJ (2004) Penetration of Candida biofilms by antifungal agents. Antimicrob Agents Chemother 48: 3291-3297. doi: 10.1128/AAC.48.9.3291-3297.2004

Budzyńska A, Sadowska B, Więckowska-Szakiel M, Różalska B (2014) Enzymatic profile, adhesive and invasive properties of Candida albicans under the influence of selected plant essential oils. Acta Biochim Pol 61: 115-121.

Busch S, Bode HB, Brakhage AA, Braus GH (2002) Impact of the cross-pathway control on the regulation of lysine and penicillin biosynthesis in Aspergillus nidulans. Curr Genet 42: 209-219. doi: $10.1007 /$ s00294-002-0333-8

Drenkard E (2003) Antimicrobial resistance of Pseudomonas aeruginosa biofilms. Microbes Infect 5: 1213-1219. http://dx.doi.org/10.1016/j. micinf.2003.08.009

Chandra J, Kuhn DM, Mukherjee PK, Hoyer LL, McCormick T, Ghannoum MA (2001) Biofilm formation by the fungal pathogen Candida albicans: development, architecture, and drug resistance. $J$ Bacteriol 183: 5385-5394. doi: 10.1128/JB.183.18.5385-5394.2001

Chen X, Wu H, Cao Y, Yao X, Zhao L, Wang T, Yang Y, Lv D, Chai Y, Cao Y, Zhu Z (2014) Ion-pairing chromatography on a porous graphitic carbon column coupled with time-of-flight mass spectrometry for targeted and untargeted profiling of amino acid biomarkers involved in Candida albicans biofilm formation. Mol BioSyst 10: 74-85. doi: $10.1039 / \mathrm{c} 3 \mathrm{mb} 70240 \mathrm{e}$

Ernst EJ, Rogers PD (2005) Antifungal Agents: Methods And Protocols (Methods in Molecular Medicine). Humana Press Inc.

Gabriel I, Vetter ND, Palmer DRJ, Milewska MJ, Wojciechowski M, Milewski S (2013) Homoisocitrate dehydrogenase from Candida albicans: properties, inhibition, and targeting by an antifungal pro-drug. FEMS Yeast Res 13: 143-155. doi: 10.1111/1567-1364.12014

Gabriel I, Kur K, Laforce-Nesbitt SS, Pulickal AS, Bliss JM, Milewski S (2014) Phenotypic consequences of LYS4 gene disruption in Candida albicans. Yeast 31:299-308. doi: 10.1002/yea.3021

Gillum AM, Tsay EY, Kirsch DR (1984) Isolation of the Candida albicans gene for orotidine-5'-phosphate decarboxylase by complementation of S. cerevisiae ura3 and E. coli pyrF mutations. Mol Gen Genet 198: 179-182. doi: 10.1007/BF00328721

Harrington A, McCourtney K, Nowowiejski D, Limaye A (2007) Differentiation of Candida albicans from non-albicans yeast directly from blood cultures by Gram stain morphology. Eur I Clin Microbiol Infect Dis 26: 325-329. doi: 10.1007/s10096-007-0291-7

Jastrzębowska K, Gabriel I (2015) Inhibitors of amino acids biosynthesis as antifungal agents. Amino Acids 47: 227-249. doi: 10.1007/ s00726-014-1873-1

Jayatilake JA, Samaranayake YH, Cheung LK, Samaranayake LP (2006) Quantitative evaluation of tissue invasion by wild type, hyphal and SAP mutants of Candida albicans, and non-albicans Candida species in reconstituted human oral epithelium. J Oral Pathol Med 35: 484491. doi: $10.1111 /$ j.1600-0714.2006.00435.x

Kingsbury JM, Goldstein AL, McCusker JH (2006) Role of nitrogen and carbon transport, regulation, and metabolism genes for Saccharomyces cerevisiae survival in vivo. Eukaryot Cell 5: 816-824. doi: 10.1128/EC.5.5.816-824.2006

Kojic EM, Darouiche RO (2004) Candida infections of medical devices. Clin Microbiol Rev 17: 255-267. doi: 10.1128/CMR.17.2.255-267.2004

Kur K, Gabriel I, Morschhäuser J, Barchiesi F, Spreghini E, Milewski S (2010) Disruption of homocitrate synthase genes in Candida albicans affects growth but not virulence. Mycopathologia 170: 397-402. doi: $10.1007 \%$ s11046-010-9337-y

Liebmann B, Mühleisen TW, Müller M, Hecht M, Weidner G, Braun A, Brock M, Brakhage AA (2004) Deletion of the Aspergillus fumigatus lysine biosynthesis gene lysF encoding homoaconitase leads to attenuated virulence in a low-dose mouse infection model of invasive aspergillosis. Arch Microbiol 181: 378-383. doi: 10.1007/ s00203-004-0667-3

Miceli MH, Díaz JA, Lee SA (2011) Emerging opportunistic yeast infections. Lancet Infect Dis 11: 142-151. doi: 10.1016/S14733099(10)70218-8

Palmer DRJ, Balogh H, Ma G, Zhou X, Marko M, Kaminskyj SG (2004) Synthesis and antifungal properties of compounds which target the $\alpha$-aminoadipate pathway. Pharmazie 59: 93-98.

Pierce CG, Uppuluri P, Tristan AR, Wormley FL Jr, Mowat E, Ramage G, Lopez-Ribot JL (2008) A simple and reproducible 96-well platebased method for the formation of fungal biofilms and its application to antifungals susceptibility testing. Nat Protoc 3: 1494-1500. doi: $10.1038 /$ nport.2008.141

Ramage G, Rajendran R, Sherry L, Williams C (2012) Fungal biofilm resistance. Int J Microbiol 2012: 528521. http://dx.doi. org/10.1155/2012/528521

Schaller M, Mailhammer R, Grassl G, Sander CA, Hube B, Korting HC (2002) Infection of human oral epithelia with Candida species induces cytokine expression correlated to the degree of virulence. $J$ Invest Dermatol 118: 652-657. doi: 10.1046/j.1523-1747.2002.01699.x

Schaller M, Zakikhany K, Naglik JR, Weindl G, Hube B (2006) Models of oral and vaginal candidiasis based on in vitro reconstituted human epithelia. Nat Protoc 1: 2767-2773. doi: 10.1038/nprot.2006.474

Schöbel F, Jacobsen ID, Brock M (2010) Evaluation of lysine biosynthesis as an antifungal drug target: biochemical characterization of Aspergillus fumigatus homocitrate synthase and virulence studies. Eukaryot Cell 9: 878-893. doi: 10.1128/EC.00020-10

Seneviratne CJ, Jin LJ, Samaranayake YH, Samaranayake LP (2008) Cell density and cell aging as factors modulating antifungal resistance of Candida albicans biofilms. Antimicrob Agents Chemother 52: 3259-3266. doi: 10.1128/AAC.00541-08

Silva S, Henriques M, Hayes A, Oliveira R, Azeredo J, Williams DW (2011) Candida glabrata and Candida albicans co-infection of an in vitro oral epithelium. J Oral Pathol Med 40: 421-427. doi: 10.1111/j.16000714.2010.00981.x

Tang CM, Smith JM, Arst HN Jr, Holden DW (1994) Virulence studies of Aspergillus nidulans mutants requiring lysine or p-aminobenzoic acid in invasive pulmonary aspergillosis. Infect Immun 62: 5255-5260.

Uppuluri P, Dinakaran H, Thomas DP, Chaturvedi AK, Lopez-Ribot JL (2009) Characteristics of Candida albicans biofilms grown in a synthetic urine medium. J Clin Microbiol 47: 4078-4083. doi: 10.1128/ JCM.01377-09

Wächtler B, Wilson D, Haedicke K, Dalle F, Hube B (2011) From attachment to damage: defined genes of Candida albicans mediate adhesion, invasion and damage during interaction with oral epithelial cells. Plos One 6: e17046. http://dx.doi.org/10.1371/journal. pone.0017046

Yamaki H, Yamaguchi M, Imamura E, Suzuki H, Nishimura T, Saito H, Yamaguchi H (1990) The mechanism of antifungal action of (S)2-amino-4-oxo-5-hydroxypentanoic acid, RI-331: the inhibition of homoserine dehydrogenase in S. cerevisiae. Biochem Biophys Res Commun 168: 837-845.

Yeater KM, Chandra J, Cheng G, Mukherjee PK, Zhao X, RodriguezZas SL, Kwast KE, Ghannoum MA, Hoyer LL (2007) Temporal analysis of Candida albicans gene expression during biofilm development. Microbiology 153: 2373-2385. doi: 10.1099/mic.0.2007/006163-0

Zhu Z, Wang H, Shang Q, Jiang Y, Cao Y, Chai Y (2013) Time course analysis of Candida albicans metabolites during biofilm development. J Proteome Res 6: 2375-2385. doi: 10.1021/pr300447k 